УДК 81’322.4:577.25

DOI:

Алла Ольховська, доктор педагогічних наук, професор кафедри перекладознавства імені Миколи Лукаша

Харківського національного університету імені В. Н. Каразіна

Анна Рибалка, студентка другого курсу магістратури кафедри перекладознавства імені Миколи Лукаша

Харківського національного університету імені В. Н. Каразіна

\title{
ЕКСПЕРИМЕНТАЛЬНЕ ДОСЛІДЖЕННЯ 3 ВИВЧЕННЯ ВПЛИВУ ВИКОРИСТАННЯ СИСТЕМ МАШИННОГО ПЕРЕКЛАДУ НА ЯКІСТЬ ПЕРЕКЛАДУ ТЕКСТІВ У ГАЛУЗІ НЕЙРОБІОЛОГІЇ
}

У статті описано експериментальне дослідження із вивчення особливостей впливу застосування різних систем машинного перекладу на якість перекладу текстів у галузі нейробіології. Досліджено переклади виконані трьома системами машинного перекладу, дві з яких є нейронними (PROMT.One та Amazon Translate), а інша - гібридною (Bing Microsoft Translate) в аспекті кількості помилок різного ступеню викривлення змісту тексту оригіналу. Результати дослідження, подані у порівняльних таблииях з кількісними даними, демонструють, щэо найбільш якісний переклад у галузі нейробіології виконала гібридна система Bing Microsoft Translate. Окрім визначення провідної системи для галузі, виділено загальні проблеми та труднощі систем машинного перекладу.

Ключові слова: машинний переклад; фахова компетентність перекладача; нейронні системи машинного перекладу; гібридні системи машинного перекладу; фахова підготовка перекладачів.

Табл. 4. Літ. 12.

Alla Olkhovska, Doctor of Sciences (Pedagogy), Professor of the Mykola Lukash Translation Studies Department of Kharkiv Vasyl Karazin National University Anna Rybalka, Second-year Graduate Student Mykola Lukash Translation Studies Department of Kharkiv Vasyl Karazin National University

\section{EXPERIMENTAL STUDY OF THE IMPACT OF THE USE OF MASHINE TRANSLATION SYSYTEMS ON THE QUALITY OF TRANSLATION OF TEXTS IN THE FIELD OF NEUROBIOLOGY}

The article describes experimental research which was devoted to the study of the peculiarities of the impact of the use of different machine translation systems on the quality of translation of texts in the field of neurobiology. The translations performed by three machine translation systems, two of which are neural (PROMT. One and Amazon Translate), and the other one is hybrid (Bing Microsoft Translate) were studied in the terms of the number of mistakes of varying degrees of distortion of the content of the original text. To achieve the aim of the study, we performed a number of tasks: formulated research hypotheses; selected the text of the relevant topic for the study; chose three machine translation systems; defined the procedure for assessing errors in translation texts; evaluated the translated texts in accordance with the established procedure; carried out quantitative processing of experimental data; performed data analysis and visualized them in tables; formulated conclusions and prospects for further research. Each translation performed by the machine translation systems was evaluated according to the criterion of the overall quality of the translation text and for this purpose we used the evaluation system developed by Professor Leonid Chernovaty, who suggested establishing penal points for certain types of errors. Thus, he distinguishes three types of errors: first type errors - errors that distort the content of the original text, that leads to misunderstanding of the original meaning by the recipient of the translation. For such errors 1 penal point is given. Second type of errors - errors that lead to some inaccuracies in the perception of the content of the original text and can distort it. For such errors 0.5 penal point is given. Third type errors-errors that almost do not or completely do not affect the perception of the content of the original text, so that the recipient can completely or almost completely understand the content of the original text, despite the presence of such errors. For such errors 0.1 penal point is given. The results of the study, presented in comparative tables with quantitative data, show that the best translation in the field of neurobiology was performed by the hybrid system Bing Microsoft Translate. In addition to defining a 
leading machine translation system for the field, the general problems and difficulties of machine translation systems are outlined.

Keywords: machine translation; translation competence; neural machine translation systems; hybrid machine translation systems; professional training of translators.

П остановка проблеми. У процесі глобалізації та розвитку інформаційнокомунікаційних технологій вимоги до роботи перекладача змінилися. Сьогодні володіння системами машинного перекладу складає обов'язкову частину інструментальної компетентності перекладача. Такі зміни зумовлені вимогами ринку перекладацьких послуг, на який передовсім повинні орієнтуватися при складанні програм підготовки майбутніх перекладачів у закладах вищої освіти [5]. Проте питання впливу таких систем на переклад текстів у різних галузях та місце перекладача при роботі 3 ними все ще залишаються недостатньо дослідженими. Порівняння роботи різних систем машинного перекладу є важливим, оскільки дає змогу перекладачам не витрачати час на пошуки відповідної системи машинного перекладу, а такожсформулювати висновки щодо ключових особливостей такої роботи.

Аналіз основних досліджень і публікацій. Нейробіологія $\epsilon$ молодою галуззю науки, що стрімко розвивається і часто стає об'єктом досліджень. Оскільки нейробіологія - наука міждисципліна, що виникла на стику медицини, біології, фармакології, психології, когнітивістики тощо, можна знайти релевантні, у рамках нашого дослідження, праці, що, зокрема, вивчають: проблеми перекладу медичних термінів [4], переклад термінів-епонімів [1], особливості перекладу фармацевтичних текстів [2], вимоги до перекладу наукових текстів [7], особливості науково-популярного стилю [9].

Усі перелічені праці зробили значний внесок у дослідження перекладу текстів обраних тематик, проте ми не знайшли таких праць, що безпосередньо вивчали б переклад у галузі нейробіології, а особливо вплив різних систем машинного перекладу на якість виконання перекладу в цій галузі. Інтерес до нейробіології останніми роками стрімко зростає, як серед науковців, так і серед нефахівців, що дізнаються про результати досліджень з численних науковопопулярних книжок. Про це свідчить зростання кількості, виданих книжок за останнє десятиріччя [12]. Такий жвавий інтерес до обраної тематики i необхідність шукати відповіді на питання щодо того, як насправді системи машинного перекладу впливають на роботу перекладачів і чи здатні вони виконувати переклад у галузі нейробіології на достатньо високому рівні, зумовлюють актуальність нашого дослідження.

Метою дослідження $є$ порівняння впливу нейронних і гібридних систем машинного перекладу на якість перекладу текстів у галузі нейробіології в аспекті кількості помилок різного ступеню викривлення змісту тексту оригіналу.

Реалізація сформульованої нами мети передбачає розв'язання низки завдань:

- сформулювати гіпотези дослідження;

- обрати текст у галузі нейробіології для проведення дослідження;

- обрати три системи машинного перекладу;

- визначити процедуру оцінювання помилок у текстах перекладу;

- провести оцінку текстів перекладу згідно зі встановленою процедурою;

- провести кількісну обробку одержаних експериментальних даних;

- виконати аналіз даних та унаочнити їх у таблицях;

- сформулювати висновки та перспективи подальших досліджень.

Матеріалом дослідження є три тексти перекладу уривків з книги у галузі нейробіології, виконані трьома системами машинного перекладу PROMT.One, Amazon Translate тa Bing Microsoft Translator.

Для реалізації визначеної мети ми скористалися низкою методів, зокрема критичного аналізу, узагальнення, порівняльного аналізу, інформаційнопошуковим методом та кількісної обробки експериментальних даних.

Виклад основного матеріалу. Експериментальне дослідження зі вивчення впливу використання систем машинного перекладу на переклад текстів у галузі нейробіології було проведено у декілька етапів: програмуючий, інформаційний, аналітичний та практичний $[6,44]$. На програмуючому етапі ми сформулювали гіпотези дослідження:

- гіпотеза 1: якість перекладу тексту у галузі нейробіології в аспекті передачі змісту тексту буде вищою при застосуванні системи машинного перекладу PROMT.One 3 налаштуванням "Медицина";

- гіпотеза 2: якість перекладу тексту у галузі нейробіології в аспекті передачі змісту тексту буде вищою при застосуванні системи машинного перекладу Amazon Translate;

- гіпотеза 3: якість перекладу тексту у галузі нейробіології в аспекті передачі змісту тексту буде вищою при застосуванні системи машинного перекладу Bing Microsoft Translator.

Матеріалом для виконання машинного 
Таблиця 1.

Результати виконання перекладу у галузі нейробіології системою машинного перекладу PROMT.One $з$ налаштуванням "Медицина"

\begin{tabular}{|c|c|c|c|c|}
\hline Типи помилок & $\begin{array}{l}\text { Кількість штрафних } \\
\text { балів }\end{array}$ & $\begin{array}{l}\text { Питома вага } \\
\text { штрафних балів }\end{array}$ & $\begin{array}{l}\text { Кількість } \\
\text { помилок }\end{array}$ & $\begin{array}{l}\text { Питома } \\
\text { вага } \\
\text { помилок }\end{array}$ \\
\hline 1й тип & 155,0 & $58,14 \%$ & 155 & $30,1 \%$ \\
\hline 2й тип & 94,5 & $35,45 \%$ & 189 & $36,7 \%$ \\
\hline Зй тип & 17,1 & $6,41 \%$ & 171 & $33,2 \%$ \\
\hline Разом & 266,6 & & 515 & \\
\hline
\end{tabular}

Таблиця 2.

Результати виконання перекладу у галузі нейробіології системою машинного перекладу Amazon Translate

\begin{tabular}{|c|c|c|c|c|}
\hline Типи помилок & $\begin{array}{l}\text { Кількість штрафних } \\
\text { балів }\end{array}$ & $\begin{array}{l}\text { Питома вага } \\
\text { штрафних балів }\end{array}$ & $\begin{array}{l}\text { Кількість } \\
\text { помилок }\end{array}$ & $\begin{array}{l}\text { Питома } \\
\text { вага } \\
\text { Помилок }\end{array}$ \\
\hline 1й тип & 139,0 & $54,6 \%$ & 139 & $23,9 \%$ \\
\hline 2й тип & 89,0 & $35,0 \%$ & 178 & $30,5 \%$ \\
\hline Зй тип & 26,6 & $10,4 \%$ & 266 & $45,6 \%$ \\
\hline Разом & 254,6 & & 583 & \\
\hline
\end{tabular}

перекладу ми обрали уривки текстів у галузі нейробіології англійською мовою 3 книги "Тhе Brain's Way of Healing. Remarkable Discoveries and Recoveries from the Frontiers of Neuroplasticity" [10] обсягом 20826 друкованих знаків та їх офіційний переклад українською мовою [3] як еталонний переклад. Відбір уривків здійснювався за принципом найбільшої насиченості термінологією у галузі нейробіології.

Для проведення дослідження були обрані такі системи машинного перекладу (МП): PROMT.One 3 налаштуванням "Медицина", нейронна система Amazon Translate та гібридна Bing Microsoft Translator.

Три переклади, виконані системами МП, були оцінені із застосуванням системи оцінювання якості перекладів, розробленої професором Л. Черноватим [8, 229-234], а саме:

- 1 тип помилок. Такі, що значно змінюють зміст тексту оригіналу (ТО). Оцінюються у 1 штрафний бал.

- 2 тип помилок. Такі, що потенційно можуть викривити зміст ТО та вплинути на його розуміння адресатом перекладу. Оцінюються у 0,5 штрафного балу.
- 3 тип помилок. Такі, що впливають незначно мірою, або не впливають зовсім на зміст ТО. Оцінюються у 0,1 штрафного балу.

Після оцінювання якості перекладів за вищезазначеними критеріями ми звели інформацію про кількість помилок, штрафних балів та їх питому вагу у порівняльну таблицю для кожної системи МП.

Система машинного перекладу PROMT.One з налаштуванням “Медицина” виконала переклад зі значною кількістю помилок першого типу. Їх питома вага серед помилок іншого типу складає $30,1 \%$, що $є$ найвищим показником серед трьох обраних нами систем. Ступінь викривлення змісту ТО у перекладі засобами цієї системи є найбільшим.

Загальна кількість помилок у перекладі, виконаному системою машинного перекладу Amazon Translate вища, ніж у PROMT.One 3 налаштуванням “Медицина”, проте кількість штрафних балів стала нижчою. Це пояснюється зменшенням помилок 1 типу, що також вказує на вищий ступінь збереження змісту ТО.

У тексті перекладу, виконаному Bing Microsoft Translator, загальна кількість помилок також 
Таблиця 3.

Результати виконання перекладу у галузі нейробіології системою машинного перекладу Bing Microsoft Translator

\begin{tabular}{|l||l|l|l|l|}
\hline Типи помилок & $\begin{array}{l}\text { Кількість } \\
\text { штрафних балів }\end{array}$ & $\begin{array}{l}\text { Питома вага } \\
\text { штрафних балів }\end{array}$ & $\begin{array}{l}\text { Кількість } \\
\text { помилок }\end{array}$ & $\begin{array}{l}\text { Питома вага } \\
\text { помилок }\end{array}$ \\
\hline 1 й тип & 130,0 & $54,6 \%$ & 130 & $22,8 \%$ \\
\hline 2й тип & 80,0 & $33,6 \%$ & 160 & $49,1 \%$ \\
\hline 3й тип & 28,0 & $11,8 \%$ & 280 \\
\hline Разом & 238,0 & & 570 \\
\hline
\end{tabular}

Таблиця 4.

Результати виконання перекладу у галузі нейробіології системами машинного перекладу PROMT.One з налаштуванням "Медицина", Amazon Translate тa Bing Microsoft Translator

\begin{tabular}{|l|l|}
\hline Система машинного перекладу & Загальна кількість штрафних балів \\
\hline PROMT.One з налаштуванням “Медицина” & 266,6 \\
\hline Amazon Translate & 254,6 \\
\hline Bing Microsoft Translator & 238,0 \\
\hline
\end{tabular}

перевищує кількість помилок у тексті перекладу, виконаному MП PROMT.One $з$ налаштуванням “Медицина". Але саме у цьому перекладі найнижча кількість штрафних балів, що говорить про якісніше виконання перекладу.

Висновки. Після проведення підрахунків, ми дійшли висновку, що система МП Bing Microsoft Translator впоралася краще із поставленою метою i зробила якісніший переклад тексту у галузі нейробіології, тобто підтвердилася гіпотеза 3. Найбільшу кількість у цьому перекладі становлять помилки 3 типу, такі що майже не впливають на розуміння змісту ТО. Це свідчить про те, що при подальшому постредагуванні такого тексту перекладу перекладачеві знадобиться менше часу та зусиль. Таким чином, підтвердилася гіпотеза 3: якість перекладу тексту у галузі нейробіології в аспекті передачі змісту тексту виявилася вищою при застосуванні системи машинного перекладу Bing Microsoft Translator.

Переклад, виконаний засобами Bing Microsoft Translator, не мав надто високого ступеня викривлення змісту ТО, зберігав більшість важливих моментів, що позитивно вплинуло на його розуміння. Проте такий переклад, звісно, не був ідеальним іпотребував подальшого постредагування людиною для виправлення усіх помилок.

Ми пов'язуємо такий результат з тим, що Bing Microsoft Translator $€$ єдиною гібридною системою
МП з трьох обраних нами. Такі системи часто мають певні переваги над іншими, оскільки поєднують у собі різні підходи і алгоритми, а отже, здатні компенсувати недоліки одна одної [11]. Проте за результатами нашого обмеженого у обсязі та галузі дослідження не можна зробити висновок, що гібридні системи МП є кращими за інші системи МП і здатні виконувати якісні переклади. Це питання все ще потребує подальших глибоких досліджень.

Також важливим завданням дослідження було проаналізувати та класифікувати типові помилки систем МП, що часто зустрічалися у перекладі тексту у галузі нейробіології. У ході дослідження ми відзначили, що майже усі помилки були результатом дослівного перекладу та копіювання структури речень тексту оригіналу. Звідси випливають майже усі типові помилки, а саме неврахування контексту, що призводить до неправильного розв'язання проблеми лексичної полісемії, порушення норм мови перекладу, неспроможність виконати контекстуальні заміни, недотримання стилістичної єдності тексту та нерозпізнавання термінів.

Перспективи подальших досліджень полягають у вивченні за розробленим у нашому дослідженні алгоритмом впливу різних систем машинного перекладу на переклад текстів інших тематик, виявлення ключових проблем i труднощів машинного перекладу та надання 
рекомендацій щодо упровадження систем машинного перекладу до фахової підготовки майбутніх перекладачів.

\section{ЛІТЕРАТУРА}

1. Бицко Н. І. Епонімійна медична термінологія (інтерпретація за лексико-стилістичними особливостями). Науковий вісник Міжнародного гуманітарного університету. Серія “Філологія”. 2017.№27(1).С. 125-127.

2. Боцман А. В. Структурно-семантичні та прагматичні особливості фармацевтичних текстів (на матеріалі англомовних інструкцій до вживання лікарських препаратів) : автореф. дис. на здобуття наук. ступеня канд. філол. наук : спец. 10.02.04. Київ, 2006. 20 с

3. Додж. Д. Самовідновлення мозку. Київ : Наш формат, $2020.416 \mathrm{c}$

4. Макаренко Ю. Г., Ткаченко І. В. До проблеми перекладу медичних термінів в науковому англомовному медичному тексті. Наукові записки Міжнародного гуманітарного університету: матеріали щоріч. звітн. конференц. професор.-виклад. складу Міжнародного гуманітарного університету (Одеса, 16 травня 2014 р.). Одесса, 2014. Ч. 2. С. 258-261.

5. Ольховська А. С. Аналіз сучасного перекладацького ринку як основа для побудови методики навчання перекладу. Молодь і ринок. 2016. № 3. С. 94-100.

6. Основи методології та організації наукових досліджень : навч. посіб. / за ред. А. Є. Конверського. Київ : Центр учбової літератури, 2010. 352 с.

7. Рибалко І. В., Ткач Л. М. Особливості перекладу наукових текстів : навч. посіб. Дніпропетровськ : НМетАУ, 2013. 52 c

8. Черноватий Л. М. Методика викладання перекладу як спеціальності. Вінниця : Нова Книга, 2013. $376 \mathrm{c}$

9. Четверікова О.Р.Комунікативні талінгвокультурологічні передумови дослідження науково-популярного тексту. Науковий вісник Ізмаӥльського державного гуманітарного університету. 2016. Вип. 35. С. 178-183.

10. Doidge N. The Brain's Way of Healing. Remarkable Discoveries and Recoveries from the Frontiers of Neuroplasticity. New York : Penguin Group, 2015. 308 p.

11. Nemeth G. Machine translation: a short overview. 2019. URL: https://towardsdatascience.com/machinetranslation-a-short-overview-91343ff39c9f (Accessed 09.11.2021).

12. Neuroscience Published in Decade: 2010s. URL: https://www.goodreads.com/list/s how/ 131924.Neuroscience Published in Decade 2010s (Accessed 10.11.2021).

\section{REFERENCES}

1. Bytsko, N. I. (2017). Eponimiina medychna terminolohiia (interpretatsiia za leksyko-stylistychnymy osoblyvostiamy) [Eponymous medical terminology (interpretation by lexical and stylistic features)]. Scientific journal of the International Humanitarian University. Series: philology. Vol. 27 (1), pp. 125-127. [in Ukrainian].

2. Botsman, A. V. (2006). Strukturno-semantychni ta prahmatychni osoblyvosti farmatsevtychnykh tekstiv (na materiali anhlomovnykh instruktsii do vzhyvannia likarskykh preparativ) [Structural-semantic and pragmatic features of pharmaceutical texts (based on Englishlanguage instructions for the use of drugs)]. Extended abstract of candidate's thesis. Kyiv, 20 p. [in Ukrainian].

3. Dodzh, D. (2020). Samovidnovlennia mozku [Selfhealing of brain]. Kyiv, 416 p. [in Ukrainian].

4. Makarenko, Y. H. \& Tkachenko I. V. (2014). Do problemy perekladu medychnykh terminiv v naukovomu anhlomovnomu medychnomu teksti [To the problem of translation of medical terms in a scientific English medical text]. Scientific notes of the International Humanitarian University. Proceedings of the annual reporting conference of the professors and teaching staff of the International Humanitarian University. Odessa. Part 2, pp. 258-261. [in Ukrainian]

5. Olkhovska, A. (2016). Analiz suchasnoho perekladatskoho rynku yak osnova dlia pobudovy metodyky navchannia perekladu [Analysis of the modern translation market as a basis for building a methodology for teaching translation]. "Youth and market". Monthly scientific-pedagogical journal. Drogobych, Vol. 3, pp. 94 100. [in Ukrainian].

6. Osnovy metodolohii ta orhanizatsii naukovykh doslidzhen (2010). [Fundamentals of methodology and organization of scientific research]. A textbook (Ed.). Konverskyi, A. Y. Kyiv, 352 p. [in Ukrainian]

7. Rybalko, I. V. \& Tkach, L. M. (2013). Osoblyvosti perekladu naukovykh tekstiv : navch. posib [Features of translation of scientific texts: a textbook]. Dnipropetrovsk, 52 p. [in Ukrainian].

8. Chernovatyy, L. M. (2013). Metodyka vykladannya perekladu [Methods of teaching translation]. Vinnytsya, 376 p. [in Ukrainian].

9. Chetverikova, O. R. (2016). Komunikatyvni ta linhvokulturolohichni peredumovy doslidzhennia naukovo-populiarnoho tekstu [Communicative and linguocultural prerequisites for the study of popular science text]. Scientific journal of the Izmail State University of Humanities. Vol. 35. pp. 178-183. [in Ukrainian].

10. Doidge, N. (2015). The Brain's Way of Healing. Remarkable Discoveries and Recoveries from the Frontiers of Neuroplasticity. New York : Penguin Group. 308 p. [in English]

11. Nemeth, G. (2019). Machine translation: a short overview. Available at: https://towardsdatascience.com/ machine-translation-a-short-overview-91343ff39c9f (Accessed 09 Nov. 2021). [in English].

12. Neuroscience Published in Decade: 2010s. Available at: https://www.goodreads.com/list/show/131924. Neuroscience Published in Decade 2010s (Accessed 10 Nov.2021). [in English].

Стаття надійшла до редакції 20.11.2021

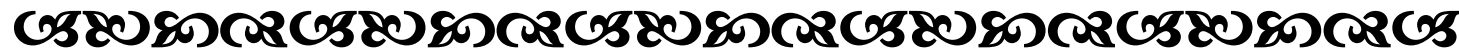

